\title{
The Effectiveness of the Combination of Visual Prompt-Fading and Direct Instruction Method in Teaching Pattern Building Skills to Students with Intellectual Disabilities
}

\author{
Meryem Uçar Rasmussen ${ }^{1}$, Müzeyyen Eldeniz Çetin ${ }^{2}$ \\ ${ }^{1}$ Abant İzzet Baysal University, Turkey \\ ${ }^{2}$ Abant İzzet Baysal University, Turkey \\ Correspondence: Meryem Uçar Rasmussen, Abant İzzet Baysal University, Turkey
}

Received: February 22, 2019

Accepted: August 14, 2019 Online Published: August 22, 2019

doi:10.11114/jets.v7i11.4472

URL: https://doi.org/10.11114/jets.v7i11.4472

\begin{abstract}
The aim of this study was to examine the effectiveness of the combination of visual prompt-fading and direct instruction method in teaching pattern building skills to students with intellectual disabilities. Three students at the age of six and seven diagnosed with intellectual disabilities and enrolled in a full-time inclusion program participated in the study, and multiple-probe design across subjects used to conduct the research. The dependent variable of the study was the participants' level of ability to build a pattern, and the independent variable was the combination of visual prompt-fading and direct instruction method. The data has been collected using tool sets and worksheets consisting of objects and object images. Graphical analysis technique has been utilized for data analysis. The findings of the study showed that a combination of visual prompt-fading and direct instruction method was effective in teaching pattern building skills to students with intellectual disabilities, but it was limited in terms of the generalization of these skills.
\end{abstract}

Keywords: pattern building skills, student with intellectual disability, visual prompt-fading, the combination of visual prompt-fading and direct instruction method

\section{Introduction}

Mathematics is one of the most important disciplines in our lives and it is an essential part of education in school years. Many researchers point out that pattern is the cornerstone of mathematics and the basis on which all other subjects are built (Liljedahl, 2004; Papic, 2007); it is the first step in algebraic thinking, as well (McGarvey, 2012). It is also stated that pattern is a phenomenon that is tightly integrated into life because we encounter it in all aspects of life such as music, art and clothes besides mathematics, (Tanisli \& Ozdas, 2009; Kesicioglu, 2013). In our environments, there are plenty of living patterns waiting for young children to discover. Therefore, students are expected to discover this skill at an early age (Wang, 2016).

Patterning is an essential skill in early mathematics learning, especially in the development of spatial awareness, sequencing and ordering, comparison and classification. In addition, this skill is incorporate the ability to identify and describe characteristics of objects and their similarities and differences (Papic, 2007).

There are two types of patterns that most children discover in their early years; these are repeating patterns and growing patterns. A repeating pattern, which is characterized by clearly repeating units (Threlfall as cited in Liljedahl, 2004), includes a group of repeated elements as pattern grows (Warren \& Cooper, 2006). In other words, such a pattern has a cyclic structure that can be formed through the repetition of some smaller units. The basic unit is continuously repeated. This pattern can be presented in many different ways. For example, an 'A,B,A,B,..., pattern can be presented with the days of the week or a mosaic (Liljedahl, 2004), movements (e.g., sit down, stand up, sit down, stand up), sounds (e.g., drum sound, cymbal sound, drum sound, cymbal sound), and geometrical shapes (e.g., a triangle, a circle, a triangle, a circle). Repeating patterns can be categorized as: (1) Hopscotch patterns that are formed by squares aligned both horizontally and vertically in a repeated way (e.g., putting 2 blocks vertically on 2 other blocks standing side-by-side), (2) periodic patterns that are formed by repeated simple units without a certain starting or end point (e.g.; putting 2 blue squares next to 2 yellow-red squares repeatedly both horizontally and vertically in a way forming a rectangle), and (3) linear patterns that are usually formed by infinite number of repeating units in a linear way going into different directions (e.g.; piling Lego 
blocks). Linear patterns are the most common form of repetitive patterns. Growing patterns systematically increase or decrease. A pattern represents the change in a set of data which defines the relationship between sequential units and it can be seen in a variety of ways ranking from simple to complex. A pattern of sequential single numbers including $1,3,5$ can be given as an example to this (Papic, 2007).

Repeating and growing patterns promote the development of functional (Warren \& Cooper, 2006) and logical thinking in children (Barrallbo, Cabrita, Palhares, \& Vale as cited in Rodrigues \& Serra, 2015). Activities aiming at pattern discovery, completion and creation enable students to realize and learn the relationship between mathematical concepts. Thanks to such activities, they can make generalizations and predictions (Ozdemir, Dikici, \& Kultur, 2014). Generalization of patterns is one of the most effective tools supporting algebraic thinking (Chua \& Hoyles, 2014). In the early years of school life, activities related to simple repetitive patterns are carried out by using shapes, colors, movements and sounds. In general, students are expected to copy patterns, continue them, discover their rules, and find missing units in those patters (Warren \& Cooper, 2008).

In Turkey, the educational goals and objectives set for 36-72 month-old children with normal development include learning outcomes related to discovering relationship among pattern units such as being able to create a pattern with objects by looking at a model, telling missing units in a pattern, completing a pattern, and telling the rule regulating a pattern consisting of up to three units. In primary schools, on the other hand, this subject is covered at different levels based on grade level. However, the programs offered to individuals with special needs do not include any learning outcome related to patterning skills.

Research shows that children spend quite a lot of time to comprehend repeating patterns in their early ages (Warren \& Cooper, 2006). Most students can copy and continue patterns (Papic \& Mulligan, 2005). Yet, patterning can be included among the difficult mathematical skills for students with intellectual disabilities, since it requires thinking and expressing rules (Sazak-Akpinar \& Kocabiyik, 2014).

Individuals with intellectual disabilities are limited in terms of many skills necessary for independent living and they experience difficulty in acquiring many skills that individuals without special needs can easily acquire (Macduff, Krantz \& McClannahan, 2001). Generally, the most important cognitive skills that individuals with intellectual disabilities lack are attention, memory and generalization (Rosenberg, Westling \& McLeskey, 2011). In addition, they may face problems in responding to environmental prompts just like students with normal development do.

Prompt is a primary stimulant that is effective in getting a response. In other words, it is a stimulant that controls a specific response (distinctive) (Macduff, Krantz, \& McClannahan, 2001). There are various prompt types available in the literature. These include verbal/vocal prompt, visual prompt, gestural prompt, positional prompt, modelling, and manual/physical prompt (Macduff, Krantz, \& McClannahan, 2001; Alberto \& Troutman, 2003; Barnett et al., 2006). Prompts are often used to increase the likelihood of desired responses given by an individual (Alberto \&Troutman, 2003).

In order to learn new behaviors, students with intellectual disabilities often need assistance, prompts (Alberto \& Troutman, 2003) and fading strategies to divert stimulus control to the distinctive stimulus obtained naturally as a result of prompting (Cengher et al., 2016). In order to enable students to be successful, prompts can be provided starting with the most intrusive one and they can be faded systematically (Alberto \& Troutman, 2003). Prompt-fading is also known as the transfer of stimulus control (Macduff, Krantz, \& McClannahan, 2001). In this strategy, prompts are gradually reduced until target responses are obtained without any prompting (Macduff, Krantz, \& McClannahan, 2001). In other words, it means reducing the amount of help required to realize a skill or activity. The main purpose of teaching a skill is to enable a student to eventually achieve this skill independently. For instance, when a skill is taught by providing a student with assistance, it is necessary to withdraw it as soon as possible in order for the student to realize the skill on his/her own. Thus, while the student gains mastery in a skill with a certain amount of prompt, the prompt becomes less intrusive (e.g., touching on his/her hand) gradually. This way, s/he doesn't get too dependent on a particular prompt when learning a new behavior or skill (Cooper, Heron, \& Heward, 2007). Observing a systematic progression in a student's performance can tell you the correct time for prompt-fading stage. This is one of the most important points of this strategy (Earles, Carlson, \& Bock, 1998).

Fading, which is an Applied Behavior Analysis strategy (ABA), is often considered along with prompting, another ABA strategy (Cooper, Heron, \& Heward, 2007). Errorless teaching methods, in which prompting and fading strategies are commonly used, are among popular methods in applied behavior analysis. Errorless teaching methods are grouped as (a) teaching through response prompts and (b) teaching through stimulus prompts. The methods including response prompts are the ones that aim at enabling an individual to produce a desired behavior by giving participant prompts before participants' responds. By fading prompts in a variety of ways, a practitioner allows the individual to gradually respond to a presented stimulus only. This allows stimulus control to be transferred from prompt to skill. Stimulus control is a predictable and reliable response by the individual during the presence of a particular stimulus (Tekin \& Kircaali-İftar, 
2001). The methods in which stimulus prompts are used are defined as systematic modifications of target stimulus and stimulus prompts in order to facilitate acquisition (Tekin \& Kircaali-İftar, 2001). Stimulus modifications are among the methods in which stimulus prompts are used and it includes making changes in materials used to increase the likelihood that target responses will occur. The aim is to promote acquisition by transferring any skill acquired through adapted materials to authentic materials. Using training wheels to teach cycling can be given as an example (Riley, 1996). There are three types of stimulant modification methods, which are controlling prompt, shaping stimulus and fading stimulus (Tekin and Kircali-İftar, 2001). In this study, prompt-fading was used. In this method, prompts are faded by making changes in the irrelevant features of target stimulus and reducing them in order to give the target stimulus its actual shape while relevant features are kept constant. There is not much information about how to fade prompts in the literature.

If current studies on stimulus modification in the literature are reviewed, it can be seen that a limited number of studies have been exclusively conducted on this subjects. They were designed as a process in which relevant and irrelevant features of a stimulus were modified, these modifications were gradually reduced, and stimulus control was finally transferred to the natural stimulus by utilizing its original shape. In his study on the effectiveness of stimulus modifications in teaching response topography, Rilley (1996) studied with three individuals with severe intellectual disabilities and aimed to teach three skills to each participant through stimulus modifications. Modifications were made in stimuli by emphasizing the size or position of the materials to be used in the skills. Each modification was designed to draw the attention to a relevant feature. For example, a modification was made in the size of the tap head to be used to teach the skill of turning on a tap by using a bigger tap head. Requiring more turning movement, this modification drew the attention to the relevant feature of this movement. The study revealed that two of a total of nine target skills were acquired without any modifications while the other two were not. As for the remaining five skills, it was found out that the participants demonstrated a significant progress after modifications. The participants were unable to realize four of these five skills without any modification to the materials during the probe sessions, whereas they performed significantly better with the initiation of the modification process. In the study by Lorah, Crouser, Gilroy, Tincani, and Hantula (2014), four participants with autism were taught how to distinguish illustrated symbols by using an Ipad and some modifications were made in the program used. Likewise, Hetzroni and Shalem (2005) utilized a seven-step fading process in their study including six participants with autism which aimed at teaching the participants to recognize text symbols from commercial logos of food products with a computer program, and it was observed that the participants were able to gain the skills at the end of the study. Another similar study conducted by Luiselli (2000) aimed at improving school attendance of a five-year girl with Asperger's syndrome through fading strategy. The duration of her mother's presence in the classroom was systematically reduced and ended, whereas the duration for which the child was present in the classroom without her mother was increased. Rincover (1978) also used stimulus fading in his/her study that involved eight participants with autism. Furthermore, visual stimulus fading was applied in teaching colors to participants with autism (Schreibman \& Charlop, 1981; Luiselli \& Donellon, 1980). For some reasons such as the difficulty of modifying stimuli, stimulus modification is not used as commonly as response prompts in educational settings, so the number of related studies is limited (Riley, 1996; Tekin-İftar \& Kircaali-İftar, 2006)

Compared to stimulus prompts, there is much more research on methods including response prompts that aim to compare the effectiveness of these methods. It has been observed that a variety of methods like most-to-least prompting, least-to-most prompting, simultaneous prompting and constant time delay procedure were employed to teach discrete and chained skills in these studies. In this study, stimulus prompting was addressed due to the limited number of available studies on this subject in the literature.

When the studies on pattern building available in the literature were reviewed, it was seen that they dealt with teaching patterning skills to children with normal development at different ages, telling rules governing various patterns, explaining their structures, the functional relations in them; creating patterns with kindergarten children (Wang, 2016), analyzing preschool children's patterning skills based on different variables (Kesicioglu, 2013), kindergarten, first grade and second grade teachers' assumptions regarding patterning, criteria they use to distinguish patterns, pattern structures and sysems (McGarvey, 2012), students' perceptions of mathematical patterning in primary school (Yaman, 2010; Yaman \& Umay, 2013), 4-6 year-old children's ability to identify pattern structures, form patterns and generalize rules to other settings as a result of direct instruction method (Papic, 2007), the relationship between repeating patterns and functional thinking for primary school pupils (Warren \& Cooper, 2006), teaching repeating patterns including numbers and geometrical shapes with direct instruction method (Liljedahl, 2004), the ability of students at kindergarten and in the first, second, third, fourth and fifth grades to identify and express functional relations in a pattern (Blanton \& Kaput, 2004), the ability of students in the third, fourth and fifth grades to continue a pattern, express relationships among pattern units, and the strategies they use to do so (Looney, 2004), how generalization of different patterns are done by students at different ages and the related processes they go through; thinking processes and strategies that four-year old children use to identify rules governing repeating and growing patters, building such patterns and generalizing them and the factors 
defining these patterns (Rodrigues \& Serra, 2015), secondary school students' ability to find missing units in a pattern (Gadzichowski, O'Brien, \& Pasnak, 2014), pattern generalization processes among seventh graders (Ozdemir, Dikici, \& Kultur, 2014), generalizing pattern rules with children at the age of fourteen (Chua \& Hoyles, 2014), pattern generalizing processes of prospective math teachers (Yesildere \& Akkoc, 2011), eight-year old children's ability to generalize rules governing visual growing patterns to other models in different positions (Warren \& Cooper, 2008), high-school students' methods of generalization and the challenges they experience (Dyndial, 2007), how generalization is done in growing patterns by fifth and sixth graders (Lan Ma, 2007), how patterning related problems are generalized by second, third, fourth and fifth graders (Ley, 2005), generalization of growing patterns by seventh and eighth graders (Lin \& Yang, 2004), generalization of both growing and repeating patterns by students in the fourth grade (Warren, 1995), pattern building and generalization processes of 11 and 12 year-old students (Orton \& Orton, 1994), which strategies are used when generalizing; strategies used for pattern building and generalization by fifth graders (Tanisli \& Ozdas, 2009), strategies used for generalization by sixth graders (Becker \& Rivera, 2006), strategies used for generalization by ninth graders (Becker \& Rivera, 2005), strategies used for patterning related problems by seventh and ninth graders (Bishop, 2000), and strategies used for generalization of number patterns by students with an age range of seven and eleven (Hargreaves, Shorrocks-Taylor, \& Threlfall, 1998).

As seen above, although there are a large number of studies involving students with normal development, this number is very limited for the studies conducted with students who have special needs. Sazak-Pinar and Kocabiyik (2014) conducted a study on patterning skills of students with intellectual disabilities in Turkey. They researched the effectiveness of direct instruction method in teaching pattern building skills to three students with moderate intellectual disabilities.

This study is expected to be a guide for further research in the field of special education since patterning skills, which are considered to be fundamental in the development of early mathematical skills along with many others, have been addressed in a very limited number of studies in Turkey. Based on all of these, this study aimed to evaluate the effectiveness of prompt-fading strategy in teaching pattern building skills to individuals with intellectual disabilities.

For this purpose, the following questions were addressed:

1. Is a combination of visual prompt-fading and direct instruction method effective in teaching students with intellectual disabilities repetitive pattern building skills by looking at a repetitive pattern model consisting of objects and object images?

2. Are students with intellectual disabilities able to generalize the skills acquired to a worksheet (finding the missing unit in an incomplete pattern) following the completion of the instruction stage?

\section{Method}

\subsection{Research Model}

This study was designed based on the multiple-probe design across subjects. The dependent variable of the research was the level of building pattern students with intellectual disabilities, and the independent variable was using a combination of visual prompt-fading and direct instruction (modelling, guided practice and independent practice).

\subsection{Participants}

Three inclusive students with mild intellectual disabilities attending the first grade of a primary school, ages 6-7, participated in the study. Some prerequisite skills were sought in the individuals participating in the study. These were 1) knowing colors, shapes and numbers 2) being able to understand and follow instructions, and 3) attending school.

The ones who met these criteria were invited to participate in the study after obtaining written consent from their parents. Prior to the study, their parents and teachers were informed about the procedure and they were asked not to do any work related to the target skills.

One of the participants was said to have mild intellectual disability in the report by the Counseling and Research Center and participants' educational objectives were prepared accordingly, though later it was found out during the interviews held with his/her teachers that the participant had a hearing disability as well. Table 1 shows the demographic characteristics of the participants. 
Table 1. Demographic characteristics of participants

\begin{tabular}{lllll}
\hline Participant name & Grade & Age & Gender & Type Of Disability \\
\hline 1. Participant & 1. Grade & 7 & Male & Mild intellectual disability \\
2. Participant & 1. Grade & 6 & Female & Mild intellectual disability \\
3. Participant & 1. Grade & 7 & Female & Mild intellectual disability
\end{tabular}

\subsection{Instruments and Setting}

In this study six different repetitive pattern model sets were used. Three sets of patterns were created from real objects such as legos (eight yellow and eight red plastic legos about $2.5 \times 2.5 \mathrm{~cm}$ ), spoons (eight large table spoons with metal handle and sixteen small teaspoons), bottle caps (eight blue, eight white and eight purple plastic water bottles). Another three sets of patterns were created from object pictures such as picture cards with animal figures prepared by colored printing on hard cardboard of approximately $8 \times 12 \mathrm{~cm}$ (first set; eight lions, eight sheep, eight cows, second set; sixteen horses, third set; eight tigers, eight zebras and eight monkeys).

The implementation was carried out 5 days a week between 10:00 and 11:00 a.m. in a one-to-one class room at the school. The room was $2 \times 3 \mathrm{~m}$. There was a table $60 \times 100 \mathrm{~cm}$ made from wood, two wooden chairs and a wooden bookshelf $(80 \times 220 \mathrm{~cm})$ in the room.

\subsection{Data Collection Tools}

In the research, a single row data record form was used in the baseline phase, intervention phase, probe phase and generalization phase. During the baseline, instruction and probe phases of the study, six tool sets consisting of pattern models created by using two and three objects and object images were used.

For each pattern set of six different pattern models there was a record form with 8 rows to save a total of 8 pattern steps. The data recording form used in the baseline phase, intervention phase, probe phase and generalization phase aims to record whether the 8 pattern steps were successfully performed by the participant. If the participant completes the first step of the pattern (+), or if not (-), this data is then processed in the record column.

In the generalization phase, the participants were expected to generalize the building patterns onto paper. For this purpose, four different worksheets were used, each with six different repetitive pattern models. Data collection forms and data record tables were prepared for each phase.

\subsection{Implementation Process}

The model was implemented as follows: To collect baseline data, at least four sessions were held with all the participants simultaneously until stable data was obtained. Once the data stability was achieved for all of them, the intervention phase was initiated. During the intervention phase, teaching sessions were started with the first participant while no instruction was provided to the second and third participants. After the first participant achieved the set criteria and stable data was obtained, the intervention phase was ended; then, the first probe sessions were initiated with all participants simultaneously. When stable data was collected during four consecutive sessions from all participants simultaneously, this phase came to an end and the intervention phase was initiated for the second participant. No instruction was provided to the first or third participant at this stage. When the second participant met the set criteria and stable data was obtained, the intervention sessions for this participant were ended and the second probe phase was initiated for all participants simultaneously. Once stable data was obtained during four consecutive sessions from all participants simultaneously, this probe phase finished and intervention phase was started for the third participant. No teaching was done with the first or second participant at this stage. When the third participant fulfilled the target criteria and stable data was collected, the intervention sessions for this participant were ended and the third probe phase was initiated for all participants simultaneously. After collecting stable data in four consecutive sessions simultaneously in the third probe phase, this phase was terminated and the generalization phase started (Tekin-İftar, 2012). The implementation phase was ended after collecting data in one generalization session. Further details about these phases are given below.

\subsubsection{Baseline Phase}

The baseline data was collected using a total of six sets of tools, consisting of three different tool sets including objects and object images. The same tool sets were used during the intervention and probe phases. Baseline data was simultaneously collected with all participants until data stability was achieved in four consecutive sessions (one session per day).

After giving the tool set to the participants, they were instructed to "build the pattern". No reaction was given upon any correct or incorrect response. After each session, they were reinforced by thanking for their participation. The data was 
recorded in data collection forms. When at least three stable data points were obtained consecutively with the first, second and third participants, the teaching process was started.

\subsubsection{Intervention Phase}

The same sets of tools used to collect baseline level data were utilized in the intervention phase. Teaching sessions, which were held five days a week between 10:00 a.m. and 11:00 a.m., lasted for 20 minutes on average. In the resource room, where teaching sessions were held, the practitioner sat facing the participants. Tool sets were kept ready in a box next to both the participant and the practitioner. In each session, six different tool sets consisting of objects and object images were used.

\section{The process of visual prompt-fading:}

In the research an 8-step model was used to teach the participants how to built a pattern based on visual prompt-fading. In the fading process, to fade the stimulus, the amount of units of the pattern model was gradually decreased with every new teaching session, from 8 units to 6, 4, 2 and finally 0 units over 5 stages from a full model to no model. For example with the first tool set, the unit pattern consisted of one yellow followed by one red lego, and the entire model repeated this pattern 8 times. For the second tool set, the unit pattern consisted of one table spoon, followed by two tea spoons. Again this unit was repeated 8 times to create the complete model. For every session the participant was then expected to create the same 8-step pattern from a gradually fading model. The teaching started by showing the participant the 8-step pattern model and the participant was expected to create the same 8-step pattern by looking at the model. This was the first stage of process. If the participant completed the 8 steps, the steps of the model were decreased by two units for the next session. Thus for the second stage of the process the fading started, and the participant was only given a 6-step pattern model, but still expected to complete the original 8-step pattern. If completed by looking at the 6-step model, the steps of the model was again decreased by two units for the next session. For this third stage of the process, the participant was only shown a 4-step model and still expected to complete all 8 steps by looking at the 4- step model. If again completed, for the fourth stage of the visual fading, the participant was only given a 2-step model and expected to continue completing the 8-step pattern by looking at the 2-step model. Finally for the fifth and last stage of the process, the participant was not given any model, but still asked to complete the original 8-step pattern without any visual model.

\section{The process of combining visual prompt-fading and direct instruction:}

In the teaching process of the research, visual prompt-fading and the direct instruction are presented together. In each session, participants were asked to create six different patterns with six different tool sets.

Below is the explanation regarding the use of one single tool set in an eight-step pattern model. For the other five sets of tools, the same process was followed in a row; intervention and assessment were done and prompt-fading was applied.

1- The practitioner said "Today, we will learn how to build a pattern with you" to the participant. Then the practitioner drew the participant's attention to the work to be done by saying "We can begin if you are ready," and started when the participant said s/he was.

2- An eight-step tower model consisting of a total of 16 Lego blocks ( 8 yellow and 8 red) was placed in front of the participant and was given the opportunity to examine the model and layed out the first tool set, consisting of the lego blocks needed to build the model.

3- Afterwards, the participant was given a short explanation about the model pattern and its rule. The practitioner told the participant that "There is a pattern rule among the Lego blocks used in this model. The rule of this pattern is a yellow Lego block followed by a red one. You see? Yellow, red, yellow, red. Then the teacher said "Lets build the tower together", modelling the pattern to the participant.

4- After modelling to the participant, the teacher turned to guiding, saying "Now, it is your turn to build the same pattern using the blocks in front of you" and then the practitioner gave the participant the opportunity to perform the pattern steps correctly by looking at the model. Each step that the participant performed correctly was reinforced by saying, "Well done, very good." When the participant did it wrong, s/he was guided with error-correction by saying "let's do it again by looking at our model and the rule of our pattern."

5- To assess the ability to build the pattern independently by looking at the 8-step model, the participant was asked to build the pattern, now without guided support from the teacher. At this stage, no reaction was given upon the participant's response, whether correct or incorrect. If the participant was not able to create the whole model with $75 \%$ accuracy or above, the teaching was repeated and the assessment was made again in the next session using the same 8-step pattern model. The participant was considered able to build the 8-step pattern independently, if an accuracy of $75 \%$ or above was reached. 
6- After reaching the required pattern model accuracy, visual-prompt fading was then applied, so the next teaching session was conducted based on a six-step pattern model, thus reducing the visual-prompt (reducing the steps of the model).

7- Once teaching and assessment were over with the first tool set, the process continued with the next tool set, for which, the same process was followed. Having followed the same procedure and completed the sessions, the practitioner thanked each participant for his/her participation and reinforced them uttering the statement mentioned before.

Upon the completion of intervention phase, the data obtained through those sessions were recorded on the data collection form.

\subsubsection{Probe Phase}

The same tool sets which had been used in the baseline and intervention phases were utilized in the probe phase and the same process as the one in the baseline phase was followed to collect data. The forms and record tables developed for baseline data collection were used for probing, as well. Probe phases consisting of four sessions were simultaneously carried out with all participants after the completion of each participant's intervention phase. The data obtained were recorded in the data collection forms, which were prepared separately for each probe phase.

\subsubsection{Generalization Phase}

Following the third probe phase, a simultaneous generalization session was held with each participant for data collection. For this purpose, the same process was followed and no modeling was provided by the practitioner. However, at the end of the session, the participants were verbally reinforced and rewarded.

Different from the tool sets used in the intervention and probe sessions, worksheets were utilized in the generalization phase. Four different worksheets were prepared to be used in each session. Each worksheet was composed of six different patterns prepared with shapes such as geometric shapes, clouds, sun, moon and flowers. In addition, a different approach was employed in this phase; the participants were asked to find the missing units in the patterns given in the worksheet and complete them rather than build a pattern using images or objects by looking at a model. The data obtained was recorded in the data collection form.

\subsection{Data Analysis}

The analysis of single-subject research data is graphical (Tekin-İftar, 2012). Therefore, the data that was obtained as a result of this study aiming at teaching "pattern-building" skills was graphically analyzed. A line graph, one of graphical analysis techniques, was used in analyzing the data.

The data which was recorded in the data collection forms prepared for the baseline, intervention, probe and generalization phases were analyzed to be processed in a graph after the implementation process. In the analysis of these data, the percentages of correct responses were calculated by dividing the number of correct responses by the total number of steps and then multiplying it with 100 .

\section{Reliability analysis}

In this study, data on both interrater reliability (dependent variable reliability) and procedural reliability (independent variable reliability) was collected. In order to measure the related scores, $30 \%$ of the intervention sessions held with each participant were arranged through random method. These sessions were observed by a $\mathrm{PhD}$ student in the field of special education, who recorded the data in the data collection form. Interrater reliability was calculated using the formula "Agreement/ [Agreement + Disagreement] x 100". Procedural reliability percentage, on the other hand, was calculated using the formula "Observed behavior/Target behavior x 100" (Tekin-İftar, 2012).

The interrater reliability average of the study was measured as $96 \%$ (90\% for the first participant, $99 \%$ for the second participant, $100 \%$ for the third participant). In addition, the procedural reliability average was found to be quite high with $\% 93$ (90\% for the first participant, 100\% for the second participant and 90\% for the third participant).

\section{Findings}

The data collected in this study which aimed at examining the effectiveness of the combination of visual prompt-fading and direct instruction method in teaching pattern building skills to students with intellectual disabilities were analyzed and shown on the graph given in Figure 1. The data obtained in the baseline, intervention, probe and generalization phases has been shown separately for all participants in the graph, and it has been further explained in the section following the graph. In the graph, the horizontal axis refers to the number of sessions performed with the participants, and the vertical axis represents the percentages of the participants' correct responses. 


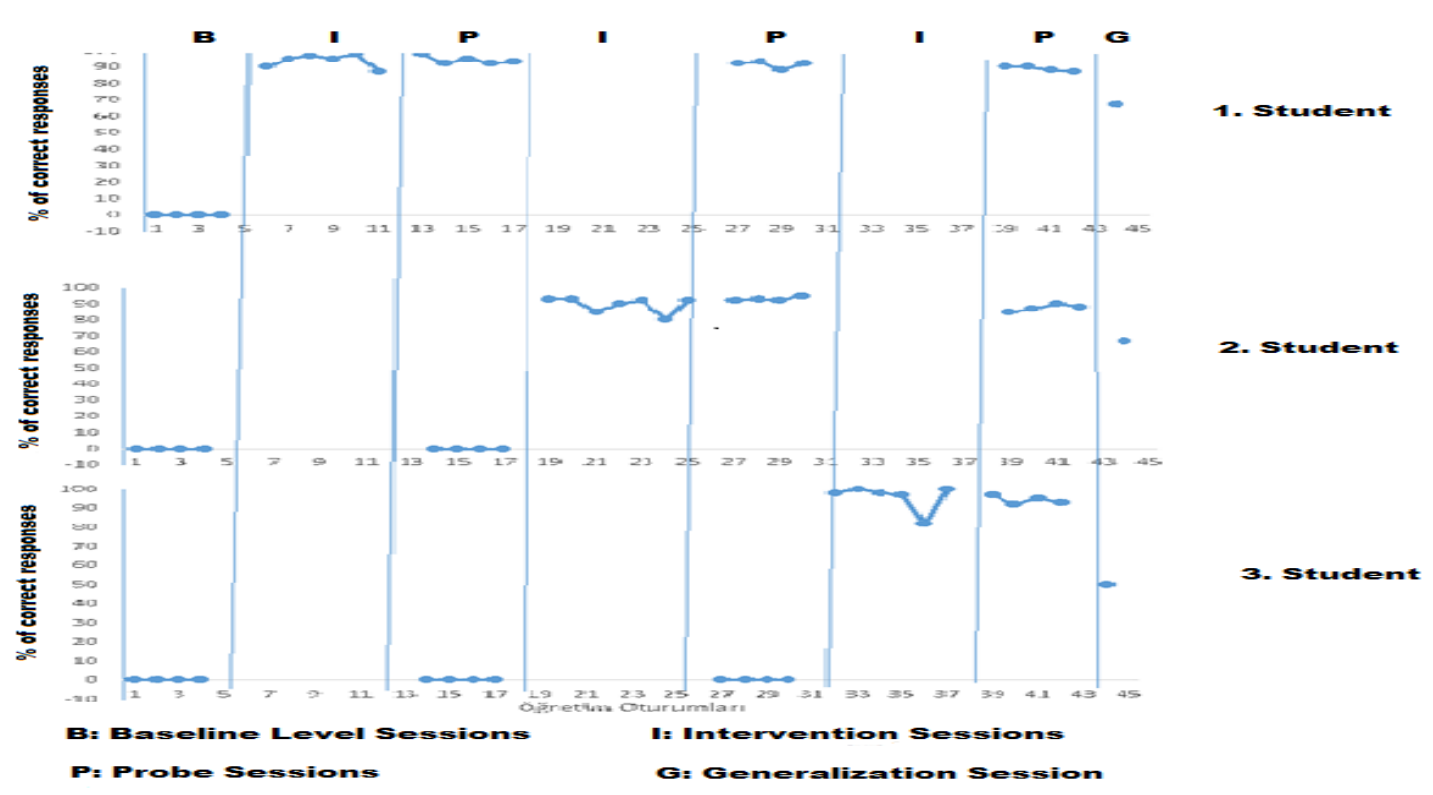

Figure 1. Percentages of the participants' correct responses in pattern building activities during the baseline (B), intervention $(\mathrm{I})$, probe $(\mathrm{P})$, and generalization $(\mathrm{G})$ phases

\subsection{Findings about the First Participant}

When the data collected in the baseline phase was examined, it was observed that the first participants' correct response average was $0 \%$ for four sessions. Following the baseline phase, seven intervention sessions were held with participant using the combination of visual prompt-fading and direct instruction method. The average of the participants' correct responses in these sessions was 94\% (respectively 90\%, 95\%, 97\%, 95\%, 98\%, 87\% and 98\%). When the data collected during the baseline phase and the intervention phase were compared, it was seen that his percentage of correct responses increased sharply and met the criteria (75\% and above); also, the participant was able to realize the target skills without any prompts. Since the participant fulfilled the target criteria, the intervention sessions were terminated and the probe phase was initiated. Participants' average of correct responses was $93 \%(92 \%, 95 \%, 93 \%$ and $93 \%$ respectively) in the first probe phase, $91 \%(92 \%, 93 \%, 88 \%$ and $92 \%$ respectively) in the second probe phase, and $89 \%(90 \%, 90 \%, 88 \%$ and $87 \%$ respectively) in the third probe phase. The probe sessions carried out after the intervention phase revealed that the participant was able to maintain the target skills by achieving a correct response rate of more than $75 \%$. As for the generalization session, the participants' average mean was $67 \%$. Therefore, it could be said that the participant was not able to meet the criteria in the generalization session different form the baseline and intervention sessions.

\subsection{Findings about the Second Participant}

When the data obtained in a total number of four baseline sessions was examined, it was observed that the second participants' correct response average was $0 \%$ in this phase. Unlike the first participant, the second participant, with a correct response average of $0 \%(0 \%, 0 \%, 0 \%$, and $0 \%$ respectively), revealed similar findings to the baseline level during the first probe session that was held right after the completion of intervention sessions of the first participant. Following the first probe phase, seven intervention sessions were held with the participant using the combination of visual prompt-fading and direct instruction method. On average, the participant responded correctly by $89 \%$ (\%93, \%93, \%85, \%90, \%92, \%80 and 92\% respectively). Based on a comparison of the data collected during the baseline and the first probe sessions with the data obtained in the intervention phase, it could be said that the participants' correct response average increased dramatically and the participant met the criteria; it was also seen that the participant could realize the target skills without any prompts. Once the participant fulfilled the target criteria, the intervention sessions were terminated and the second probe phase started. The second participant's correct response average was $93 \%(92 \%$, $93 \%, 92 \%$ and $95 \%$ respectively) in the second probe phase while this score was $87,5 \%(85 \%, 87 \%, 90 \%$ and $88 \%$ respectively) in the third probe phase. The probe sessions carried out after the intervention phase revealed that the participant was able to maintain the target skills with a correct response rate of more than $75 \%$. As for the generalization sessions, the participants' average was $67 \%$. Unlike the intervention and probe phases, the second participant was also unable to meet the criteria in the generalization session similar to the first participant. 


\subsection{Findings about the Third Participant}

When the data obtained in a total number of four baseline sessions was examined, it was observed that the third participants' correct response average was $0 \%$ in this phase. Different from the first participant, the third participant responded correctly by $0 \%(\% 0, \% 0, \% 0$ and $\% 0$ respectively) during the first probe phase which was held after the completion of the first participant's intervention phase and revealed similar results which were obtained in the participants' baseline level, just like the second participant. Right after the baseline phase, six intervention sessions were held with the third participant using the combination of visual prompt-fading and direct instruction method. On average, the participant responded correctly by $96 \%$ in these six intervention sessions (\%98, \%100, \%98, \%97, \%82 and 100\% respectively). When the data collected during the baseline, the first probe and the second probe phases was compared with the data obtained in the intervention phase, it was seen that the participants' correct response average increased sharply and the participant met the criteria ( $75 \%$ or above); the participant could achieve the target skills without any prompts, as well. As it was observed that she managed to meet the target criteria, the intervention sessions were ended and the third probe phase started. The third participant was observed to respond correctly by $95 \%$ on average $(97 \%, 92 \%, 95 \%$ and $93 \%$ respectively) during the third probe phase. The probe sessions carried out after the intervention phase revealed that the participant was able to maintain the target skills with a correct response rate of more than $75 \%$. As for the generalization sessions, the participants' correct response average was 50\%. Unlike the intervention and probe phases, the third participant was unable to meet the criteria in the generalization sessions similar to the first and second participants.

\section{Discussion and Conclusion}

The purpose in this study was to evaluate the effectiveness of the combination of visual prompt-fading and direct instruction method in teaching pattern building skills to individuals with intellectual disabilities. For this purpose, it was investigated whether the participants could built the same pattern by looking at a model prepared with objects and object images, whether they could continue a pattern with less visual prompting, and whether they could generalize the skills by completing missing units in a pattern. The findings showed that a combination of visual prompt-fading and direct instruction method was effective in teaching pattern building skills to students with intellectual disabilities, but it did not help them to meet the desired criteria when they were expected to generalize the skills. Since this research was based on single subject research model, it is limited to students who have been diagnosed with intellectual disabilities. In addition, since the completion of this study coincided with the end of the academic year, the retention data to be collected after the completion of teaching was not collected. Lack of data on retention, which refers to those students' ability to maintain their skills after the completion of intervention, could be marked as a limitation to this study. The findings were discussed below considering the purpose of this study.

In this study, a combination of visual prompt-fading and direct instruction method was utilized. Prompt-fading is very essential to prevent one's excessive dependence on prompting and thus ensure his/her independence (Cooper, Heron, \& Heward, 2007). The findings have revealed that all three participants responded correctly by $0 \%$ in the baseline and probe sessions held before the intervention phase; however, at the end of intervention, their correct response average increased dramatically and they all met the criteria (75\% or above). In addition, it was observed that all of them were able to achieve the target skills without any prompts in those sessions. Based on these data, it can be concluded that all participants were able to build the same pattern by looking at the model formed with objects and object images and they could continue the pattern when visual prompt is faded. According to these findings, it can be said that a combination of visual prompt-fading and direct instruction method is an effective strategy in teaching pattern building skills to students with mild intellectual disabilities.

When the percentages of correct responses prior to the intervention phase were compared to the percentages of the first intervention phase, it was seen that the participants' performance met the criteria with a dramatic increase. It is believed that this is a result of the effectiveness of a combination of visual prompt-fading and direct instruction method in teaching pattern building skills swiftly to students with mild intellectual disabilities in steps. There are not many studies on the effectiveness of stimulus modification in the body of literature since it is not preferred by researchers due to the fact that it requires a lot of time, equipment and planning; it is also stated that it can reveal more effective results if used with response prompts (Riley, 1996; Tekin-İftar \& Kircaali-İftar, 2006). According to Riley (1990), a study based on response prompts only which yields unsuccessful results can yield the desired results if stimulus modification is also included; therefore, a combination of these two strategies can promote the skill acquisition of a student with severer intellectual disabilities. It has been seen that there are studies conducted with individuals with different degrees and types of disabilities, but no research has been done with individuals with mild intellectual disability. Therefore, stimulus modification strategy was used for such individuals and it was found out to be effective. Nevertheless, as the degree of a disability affects success as suggested by (Riley, 1990), the effectiveness of this method may change as the type and degree of disability vary. For this reason, further studies can be done with individuals with other types and degrees of disability in the future to evaluate the effectiveness of prompt-fading method. 
Although there were no studies aiming at teaching patterning skills to individuals with special needs using a combination of visual prompt-fading and direct instruction method, Sazak-Pinar and Kocabiyik (2014) studied students' acquisition of pattern building skills taught with direct instruction method. In this study, Sazak-Pinar and Kocabiyik (2014) examined the effectiveness direct instruction method in teaching pattern building skills to students with moderate intellectual disabilities using patterns including two or three objects, object images, geometric shapes, or shapes and their level of retention after one, two and three weeks following the completion of instruction; as a result of their study, it was found out that (a) the direct instruction method was effective in teaching pattern building skills to students with moderate intellectual disabilities when patterns consisting of two or three objects, object images, geometric shapes, or shapes were used, and (b) the participants were able to retain their acquisition one, two and three weeks after the completion of instruction.

The most traditional and basic type of unit used in pattern directives is color or shape. In kindergarten and first grades, single cycles (blue, red, blue) and double cycles (circle, circle, square, square) are often used (Gadzichowski, O'Brien, \& Pascal, 2014). Rodrigues and Serra (2015) have suggested two alternatives- emphasizing a repeating unit with a color (yellow, red, red, yellow, red, red) or stating the rule of a repeating unit. Also, prompts given through questions like "What is next?" can draw attention to the combination of a repeating order (McGarvey, 2012). This study was found to be effective because both of these methods were used by the researchers.

According to Papic (2007), students with normal development can remember, copy, continue and build simple repeating patterns including two or three colors without any instruction; however, they may have difficulty when more pattern units are used since the pattern gets more complicated. Likewise, Threfall (1999) puts forward that it is easier and more common for kindergarten students to learn and build repeating AB patterns including units in different colors but the same shape compared to complex patterns with multiple features (different shape, color and size). It is believed that the sudden progress in the participants' performance observed during the first intervention sessions which were held after the baseline level in this study was a result of the appropriateness of the method and the simplicity of the pattern rule used in the study. In another study conducted by Gadzichowski, O'Brien and Pasnak (2014), a variety of pattern sets consisting of pattern units in the same shape but in two different colors (AB), pattern units in the same shape but in two different sizes (ABB), pattern units in the same shape but in three different colors $(A B C)$, pattern units including two animal images in different shapes, sizes and colors along with object images $(\mathrm{AB})$, pattern units including two animal pictures in different shapes, sizes and colors $(\mathrm{ABB})$ and pattern units including three animal pictures in different shapes, sizes and colors (ABC) were used. The examination of the number of trials in each session held in their study has revealed that participants can quickly learn and independently create repeating $\mathrm{AB}$ patterns, whereas they need more trials to build repeating $\mathrm{ABC}$ patterns, which are more complex (as cited in Rodrigues \& Serra, 2015). The findings of the study by Gadzichowski, O'Brien and Pasnak (2014) support the findings of this study. However, the study by Gadzichowski, O'Brien and Pasnak (2014) is more comprehensive than this study, in which only simple pattern units have been dealt with, which remains as a limitation to this study.

According to Warren and Cooper (2008), difficulties that many students experience at the age of puberty stem from the fact that they lack experience in areas such as pattern building and generalization. In the generalization phase of this study, by utilizing a method different from the one employed during the intervention phase (building patterns using objects and object images), the participants were asked to identify missing units of patterns given in a worksheet and complete them. The findings revealed that the participants had problems in identifying missing units and completing patterns since they did not perform at the desired level and meet the criteria. The reason is thought to be the participants' lack of experience in finding missing units in a pattern. Papic and Mulliigan (2005) have stated that some children may be able to copy and continue patterns, but they may have difficulty in creating patterns that include repeating units. Sazak-Pinar and Kocabiyik (2014) reported that lack of data on the generalization of the target skills was a limitation in their study. Many studies conducted with individuals without special needs in which various topics like generalization of pattern rules and pattern generalization strategies have been researched show that participants are successful in generalization (Warren \& Cooper, 2008; Papic, 2007; Tanisli \& Ozdas, 2009; Yaman, 2010; Yaman \& Umay, 2013; Kesicioglu, 2013; Ozdemir, Dikici \& Kultur, 2014; Chua \& Hoyles, 2014; Rodrigues \& Serra, 2015).

The findings of this study have revealed that a combination of visual prompt-fading and direct instruction method is effective in teaching pattern building skills to students with mild intellectual disability, but it is limited in generalization of these skills. Patterning, which is an essential mathematical skill, is a part of the curriculum at schools individuals with normal development go to. However, it is not included in the curriculum of the schools where individuals with special needs are educated. It is recommended that skills related to pattern building be covered in the curriculum at such schools, as well. In addition, further studies on pattern building skills can be carried out with different methods and different groups of participants. Also, the same study can be done to research the acquisition of other patterning-related skills like finding a missing pattern unit and completing it. 


\section{References}

Alberto, A. A., \& Troutman, A. C. (2003). Applied behavior analysis for teacher (6th edition), NJ: Merrill Prentice Hall.

Barnett, D. W., Bauer, A., Bell, S., Elliott, N., Haski, H., Barkley, E., .. \& Mackiewicz, K. (2006). Preschool intervention scripts: lessons from 20 years of research and practice. Journal of Speech Language Pathology and Applied Behavior Analysis, 2(2), 158-81. https://doi.org/10.1037/h0100216

Becker, J. R., \& Rivera, F. (2005). Generalization strategies of beginning high school algebra students. In Chick, H. L. \& Vincent, J. L. (Eds.). Proceedings of the 29th Conference of the International Group for the Psychology of Mathematics Education, 4, pp. 121-128. Melbourne: PME.

Becker, J. R., \& Rivera, F. (2006). Sixth graders' figural and numerical strategies for generalizing patterns in algebra (1). In Alatorre, S., Cortina, J. L., Saiz, M. ve Mendez, A. (Ed.), Proceeding of The 28th Annual Meeting of The North American Chapter of The International Group for the Psychology of Mathematics Education. 2, 95-101. Merida, Mexico: Universidad Pedagogica Nacional.

Bishop, J. (2000). Linear geometric number patterns: middle school students' strategies. Mathematics Education Research Journal, 12(2), 107-126. https://doi.org/10.1007/BF03217079

Blanton, M., \& Kaput, J. (2004). Elementary grades students' capacity for functional thinking. In M. Jonsen Hoines ve A. Fuglestad (Eds), Proceedings of the 28th Conference of the International Group for the Psychology of Mathematics Education, 2, pp. 135-142. Oslo.

Cengher, M., Shamoun, K., Moss, P., Roll, D., Feliciano, G., \& Fienup, D. M. (2016). A Comparison of the effects of two prompt-fading strategies on skill acquisition in children with autism spectrum disorders. Behavior Analysis Practice, 9, 115-125. https://doi.org/10.1007/s40617-015-0096-6

Chua, B. L., \& Hoyles, C. (2014). Generalisation of linear figural patterns in secondary school mathematics. The Mathematics Educator, 15(2), 1-30.

Cooper, J. O., Heron, T. E., \& Heward, W. L. (2007). Applied behavior analysis (2 ${ }^{\text {nd }}$ edition). Upper Saddle River, NJ: Pearson.

Dyndial, J. (2007). High school students' use of patterns and generalizations. In J. Watson \& K. Beswick (Eds), Proceedings of the 30th annual conference of the Mathematics Education Research Group of Australasia, pp. 236-245.

Earles, T., Carlson, J., \& Bock, S. J. (1998). Instructional strategies to facilitate successful learning outcomes for students with autism. Educating Children and Youth with Autism. Austin, TX: Pro-Ed.

Gadzichowski1, K. M., O'Brien1, S. E., \& Pasnak, R. (2014). Orientation of letter and number patterns. Journal of Education and Human Development, 3(2), 59-66.

Hargreaves, M., Shorrocks-Taylor, D., \& Threlfall, J. (1998). Children's strategies with number patterns. Educational Studies, 24(3). https://doi.org/10.1080/0305569980240305

Hetzroni, O. E., \& Shalem, U. (2005). From logos to orthographic symbols: A multilevel fading computer program for teaching nonverbal children with autism. Focus on Autism and Other Developmental Disabilities, 20, $201-212$. https://doi.org/10.1177/10883576050200040201

Kesicioglu, O. S. (2013). The analysis of preschoolers' skills of mathematical patterning. Mediterranean Journal of Educational Research, 13, 19-26.

Lan, M. H. (2007). The potential of patterning activities to generalization. In Woo, J. H., Lew, H. C., Park, K. S. \& Seo, D. Y. (Ed.), Proceeding of The 31st Conference of the international Group for the Psychology of Mathematics Education, 3, pp. 225-232. Seoul: PME.

Ley, A. F. (2005). A cross-sectional investigation of elementary school student's ability to work with linear generalizing patterns: The impact of format and age on accuracy and strategy choice (Unpublished M.A. thesis). Toronto, Kanada.

Liljedahl, P. (2004). Repeating pattern or number pattern: The distinction is blurred. Focus on Learning Problems in Mathematics, 26(3), 24-42.

Lin, F. L., \& Yang, K. L. (2004). Differentiation of students' reasoning on linear and quadratic geometric number patterns. In M. J. Hoines ve A. Fuglestad (Ed.), Proceedings of The 28th Conference of The International Group for The Psychology of Mathematics Education. 4, 457-464. Bergen Norway: International Group For The Psychology of Mathematics Education. 
Looney, C. L. (2004). A study of students' understanding of patterns and functions in grades 3-5 (Unpublished PhD thesis). Boston, USA.

Lorah, E. R., Crouser, J., Gilroy, S. P., Tincani, M. \& Hantula, D. (2014). Within stimulus prompting to teach symbol discrimination using an ipad® speech generating device. J. Dev. Phys. Disabil., https://doi.org/10.1007/s10882-014-9369-1

Luiselli, J. K. (2000). Case demonstration of a fading procedure to promote school attendance of a child with Asperger's disorder. Journal of Positive Behavior Interventions, 2, 47-52. https://doi.org/10.1177/109830070000200107

Luiselli, J. K., \& Donellon, S. (1980). Use of a visual stimulus fading procedure to teach color naming to an autistic child. Journal of Behavior Therapy and Experimental Psychiatry, 11, 73-76. https://doi.org/10.1016/0005-7916(80)90057-9

MacDuff, G. S., Krantz, P. J., \& McClannahan, L. E. (2001). Prompts and prompt-fading strategies for people with autism. In C. Maurice, G. Green, \& R. M. Foxx (Eds.), Making a difference: Behavioral intervention for autism (pp. 37-50). Austin, TX: Pro-Ed.

McGarvey, L.M. (2012). What is a pattern? Criteria used by teachers and young children. Mathematical Thinking and Learning, 14(4), 310-337. https://doi.org/10.1080/10986065.2012.717380

Orton, A., \& Orton, J. (1994). Student's perception and use of pattern and generalization. Proceedings of the Eighteenth Conference for Psychology of Mathematics Education, 407-414.

Ozdemir, E., Dikici, R., \& Kultur, M. N. (2014). Students' pattern generalization process: the 7th grade sample. K. $U$. Kastamonu Journal of Education, 23 (2), 523-548.

Papic, M. (2007). Promoting repeating patterns with young children. Australian Primary Mathematics Classroom, 12(3), $8-13$.

Papic, M., \& Mulligan, J. (2005). The Growth of Early Mathematical Patterning: An Intervention Study. Essential Research, Essential Practice, 2.

Riley, G. A. (1990). Prompting strategies for those with a severe mental handicap: a comparison of procedures using only response prompts with a procedure combining stimulus and response prompts. Behavioral Psychotherapy, 18, 193-206. https://doi.org/10.1017/S0141347300009691

Riley, G. A. (1996). The effectiveness of stimulus modification procedures in teaching response topography to individuals with severe developmental disability. Behavioral and Cognitive Psychotherapy, 24, 371-375. https://doi.org/10.1017/S1352465800015265

Rincover, A. (1978). Variables affecting stimulus fading and discriminative responding in psychotic children. Journal of Abnormal Psychology, 87, 541-553. https://doi.org/10.1037/0021-843X.87.5.541

Rodrigues, M., \& Serra, P. (2015). Generalizing repeating patterns: a study with children aged four. International Conference on Education in Mathematics, Science \& Technology (ICEMST), April 23-26, Antalya, Turkey.

Rosenberg, M. S., Westling, D., \& McLeskey, J. (2011) Special education for today's teachers: An introduction (2nd edition). New York: Pearson.

Sazak-Pinar, E., \& Kocabiyik, D. (2014). The effectiveness of direct instruction method in teaching pattern building skill to students with moderate intellectual disabilities. Abant Izzet Baysal University Journal of Social Sciences, 3(14), 279-298.

Schreibman, L., \& Charlop, M. H. (1981). S+ versus S- fading in prompting procedures with autistic children. Journal of Experimental Child Psychology, 31, 508-520. https://doi.org/10.1016/0022-0965(81)90033-3

Tanisli, D., \& Ozdas, A. (2009). The strategies of using the generalizing patterns of the primary school 5th. grade students. Educational Sciences: Theory \& Practice, 9(3), 1453-1497.

Tekin-İftar, E. (2012). Single-subject research in education and behavioral sciences (1st edition), Ankara: Turkish Psychological Association Publications.

Tekin-İftar, E., \& Kircaali-İftar, G. (2001). Errorless teaching methods in special education, Ankara: Turkish Psychological Association Publications.

Tekin-İftar, E., \& Kircaali-İftar, G. (2006). Errorless teaching methods in special education (3rd edition), Ankara: Turkish Psychological Association Publications. 
Threlfall, J. (1999). Repeating patterns in the early primary years. In A. Orton (Ed.), Patterns in the teaching and learning of mathematics (pp. 18-30). London: Cassell.

Wang, Q. (2016). Mathematical patterning activities in the early grades. Ohio Journal of School Mathematics, 73, 37-42.

Warren, E. (1995). The development of elementary algebraic understanding. In M. Luciano (Ed.), Proceedings of The 19th Annual Meeting of the North American Chapter of the International Group for the Psychology of Mathematics Education, 2, 98-106. Columbus, OH: USA.

Warren, E., \& Cooper, T. (2006). Using repeating patterns to explore functional thinking. Australian Primary Mathematics Classroom, 11(1), 9-14.

Warren, E., \& Cooper, T. (2008). Generalizing the pattern rule for visual growth patterns: Actions that support 8 year olds' thinking. Educational Studies in Mathematics, 67(2), 171-185. https://doi.org/10.1007/s10649-007-9092-2

Yaman, H. (2010). A study on the elementary students? perceptions of connections in mathematical patterns (PhD thesis). Ankara: Hacettepe University Institute of Social Sciences, Department of Primary Education.

Yaman, H., \& Umay, A. (20013). The elementary students' perceptions of mathematical patterns according to presentation forms. Hacettepe University Journal of Education, 28(1), 405-416.

Yesildere, S., \& Akkoc, H. (2011). Pre-Service mathematics teachers' generalization processes of visual patterns. Pamukkale University Journal of Education, 30, 141-153.

\section{Copyrights}

Copyright for this article is retained by the author(s), with first publication rights granted to the journal.

This is an open-access article distributed under the terms and conditions of the Creative Commons Attribution license which permits unrestricted use, distribution, and reproduction in any medium, provided the original work is properly cited. 